\title{
Protein Changes Associated with Induced Resistance of Neisseria gonorrhoeae to Killing by Human Serum Are Relatively Minor
}

\author{
By P. V. PATEL, ${ }^{1}$ P. M. V. MARTIN,${ }^{2}$ E. L. TAN,${ }^{3}$ C. A. NAIRN, \\ N. J. PARSONS, ${ }^{1}$ M. GOLDNER ${ }^{4}$ AND H. SMITH ${ }^{1 *}$ \\ ${ }^{1}$ Department of Microbiology, University of Birmingham, PO Box 363, \\ Birmingham B15 2TT, UK \\ ${ }^{2}$ Institut Pasteur de Bangui, BP 923, Bangui, Republique Centrafricaine \\ ${ }^{3}$ Department of Genetics and Cellular Biology, University of Malaya, \\ Kuala Lumpur, 22-11, Malaysia \\ ${ }^{4}$ Department of Microbiology, University of Toronto, Toronto, Canada
}

(Received 26 May 1987; revised 2 September 1987)

\begin{abstract}
Serum-susceptible (SS) Neisseria gonorrhoeae were induced to resistance (SR) to complementmediated killing by fresh human serum (FHS) by a small- $M_{\mathrm{r}}$ factor(s) from guinea-pig blood in $3 \mathrm{~h}$ at $37^{\circ} \mathrm{C}$, but not in the presence of bacteriostatic concentrations of chloramphenicol or neomycin, indicating that proteins mediated the acquisition of resistance. SDS-PAGE protein profiles of lysates of equal numbers of gonococci showed only two qualitative differences between SR and SS organisms, both in minor components (a protein A of about $205 \mathrm{kDa}$ in the former and not the latter and vice versa for a protein $B$ of about $16 \mathrm{kDa}$ ). Many proteins, however, including the three principal outer-membrane proteins, were present in larger amounts in SR gonococci. The lack of major changes in proteins when resistance is acquired was confirmed by immunoblotting the two protein profiles with the IgG of hyper-immune rabbit anti-SR and anti-SS sera, of rabbit anti-SR serum after absorption by SS organisms and of FHS used alone and after absorption with SS organisms. The IgM of FHS, which is responsible for most of the bactericidal activity, showed only faint reactions with a few proteins common to both SS and SR gonococci and no reactions when the FHS was absorbed with SS gonococci. This is in contrast to the strong and different reactions given with lipopolysaccharide (LPS) components of SS and SR organisms, which, prepared from the former organisms, neutralize the bactericidal activity of FHS. Hence, the relatively small protein changes accompanying induction are less likely to be directly responsible for serum resistance than the more profound LPS changes.
\end{abstract}

\section{INTRODUCTION}

The resistance of Neisseria gonorrhoeae to complement-mediated killing by fresh human serum (FHS) is important in pathogenesis (Brooks et al., 1978; Parsons et al., 1985). Gonococci obtained from humans and examined without subculture are resistant to the bactericidal action of serum (serum resistant, SR) (Ward et al., 1970). Some strains retain this property after culture but most lose it. We have been concerned with the latter type of resistance.

A serum-susceptible (SS) laboratory strain of $N$. gonorrhoeae (BS) became resistant to killing by FHS after four passages through subcutaneously implanted plastic chambers in guinea pigs (BS4) (Penn et al., 1976, 1977) but, like organisms from urethral exudates, it lost its resistance on one subculture on agar [BS4 (agar)]. Resistance was restored in vitro after incubation with guinea-pig serum, its small- $M_{\mathrm{r}}$ fractions (Veale et al., 1981), some human sera, their small- $M_{\mathrm{r}}$

Abbreviations: CAM, chloramphenicol; FHS, fresh human serum; NEO, neomycin; RBC, red blood cells; SR, serum resistant; SS, serum susceptible. 
fractions (Martin et al., 1981), and human urogenital secretions (Martin et al., 1982). These observations, and a higher percentage of inducing samples in sera from women suffering gonorrhoea than in control sera (Martin et al., 1984), indicated a possible role for resistance induction in gonorrhoea. The small- $M_{\mathrm{r}}$ inducers of guinea-pig and human sera were concentrated in fractions containing glucopeptides (Patel et al., 1984b). Lysates of human and guinea-pig red blood cells (RBC) contained more resistance-inducing activity than the corresponding sera (Patel et al., 1984a).

Recently, the determinants of the induced resistance have been investigated using strain BS4 (agar) converted to resistance by ultrafiltrates of either guinea-pig serum or RBC lysates. Alteration in LPS structure with acquisition of resistance was indicated by a change in pyocinsensitivity pattern (Winstanley et al., 1984). In fact, the LPS of SR organisms lacked a higher- $M_{\mathrm{r}}$ component, present in the LPS of SS organisms and immunoblotted by IgM of FHS (Tan et al., 1986). Since the bactericidal action of FHS was neutralized by the LPS of SS organisms (Tan et al., 1986), induction to resistance appeared to be due to loss of a target for the bactericidal IgM, namely the high- $M_{\mathrm{r}}$ LPS moiety.

This paper shows that the changes in proteins accompanying resistance induction are relatively minor.

\section{METHODS}

Neisseria gonorrhoeae. Strain BS4 (agar) was derived, stored, subcultured and counted as described previously (Veale et al., 1975; Penn et al., 1976, 1977) except that for the experiments with antibiotics GC Medium Base plus Supplement G (Institut Pasteur Production) was the medium.

Fresh human serum (FHS). This was a pooled sample from at least 10 individuals.

Test of resistance to killing by FHS. This was the method of Veale et al. (1981) as modified by Patel et al. (1984b).

Inducer of resistance to killing by FHS. For the antibiotic experiments, this was an ultrafiltrate of guinea-pig serum prepared by filtration through a YM5 Diaflo membrane (Amicon) (Patel et al., 1984b). In other experiments, a similar ultrafiltrate from a lysate of guinea pig RBC (Patel et al., 1984a) was used; about $60 \mathrm{ml}$ concentrated ultrafiltrate was obtained from $300 \mathrm{ml}$ guinea-pig blood.

The action of chloramphenicol (CAM) or neomycin sulphate (NEO) on induction of serum resistance. Strain BS4 (agar) organisms were incubated with an ultrafiltrate of guinea-pig serum for $3 \mathrm{~h}$ at $37^{\circ} \mathrm{C}$ in a defined medium (DM; Veale et al., 1981) containing $0.1 \%(\mathrm{w} / \mathrm{v})$ bovine serum albumin (BSA) as previously described for inducing serum resistance (Patel et al., 1984b), but to half of the samples maximum non-bactericidal concentrations of CAM or NEO were added to inhibit protein synthesis. Control samples contained an ultrafiltrate of serum from a non-inducing human donor (Martin et al., 1981) instead of the ultrafiltrate of guinea-pig serum.

CAM (Boehringer Mannheim) was dissolved in ethanol $(1 \mathrm{mg} \mathrm{ml}-1)$, kept at $4{ }^{\circ} \mathrm{C}$ and diluted in water for the experiments. In two separate experiments, the maximum non-bactericidal concentration of CAM was determined by incubating at $37^{\circ} \mathrm{C} \mathrm{BS4}$ (agar) $\left(1-3 \times 10^{2}\right.$ c.f.u. $\left.\mathrm{ml}^{-1}\right)$ in serial dilutions of CAM in DM (Veale et al., 1981) containing $0.1 \%$ BSA and plating out the mixture at $0,2,3,4$ and $5 \mathrm{~h}$. The concentrations used in the induction medium (see above) were $0.57 \mu \mathrm{g} \mathrm{ml}^{-1}$ (experiments 1-4, Table 1) and $0.5 \mu \mathrm{g} \mathrm{m}^{-1}$ (experiments 5-9, Table 1); water-diluted ethanol solution of CAM was added to the incubation mixture $(1: 10, \mathrm{v} / \mathrm{v})$ and the same volume of water-diluted ethanol to the control samples.

NEO (Boehringer) was dissolved in water $\left(10 \mathrm{mg} \mathrm{ml}^{-1}\right)$, kept at $4{ }^{\circ} \mathrm{C}$ and diluted with water for the experiments. The maximum non-bactericidal concentration of NEO for BS4 (agar) was determined as for CAM, but the cultures were sampled only after $5 \mathrm{~h}$ incubation. The NEO concentration in the induction media was $2.6 \mu \mathrm{g} \mathrm{ml}^{-1}$.

Preparation of SR and SS gonococci. A modification of the method of Tan et al. (1986) was used. Six Erlenmeyer flasks $(150 \mathrm{ml})$ each containing DM $(43.5 \mathrm{ml})$ received $1-3 \times 10^{8}$ viable gonococci [BS4 (agar)] from an overnight culture in BSA-free DM prepared as described by Tan et al. (1986). To each of three flasks, $6.5 \mathrm{ml}$ of the inducing ultrafiltrate of $\mathrm{RBC}$ lysate was added, and to the other three, $6.5 \mathrm{ml}$ of the ultafiltrate inactivated by adding $\mathrm{HCl}$ to $\mathrm{pH} 2$, incubating at $37^{\circ} \mathrm{C}$ for $1 \mathrm{~h}$ and readjusting the $\mathrm{pH}$ to 7.0 (Tan et al., 1986). After incubation $\left(37^{\circ} \mathrm{C}, 3 \mathrm{~h}\right.$ ) on a rotary shaker $\left(50\right.$ cycles $\left.\mathrm{min}^{-1}\right)$, samples were taken for testing for resistance to killing by FHS. The contents of each flask were then centrifuged $\left(3000 \mathrm{~g}, 4^{\circ} \mathrm{C}, 20 \mathrm{~min}\right)$ in separate tubes, the supernatants removed and the gonococci kept at $-20^{\circ} \mathrm{C}$ until the results of the test for serum resistance were known. The organisms from the flasks containing untreated ultrafiltrate were $>95 \%$ resistant (SR organisms) and those from the flasks containing acid-treated ultrafiltrate were $<5 \%$ resistant (SS organisms). The centrifuged SR and SS organisms were separately pooled in 1-1.5 ml phosphate-buffered saline (PBS; Penn et al., 1976) which then contained 8-10 $\times 10^{8}$ gonococci. They were kept at $-20^{\circ} \mathrm{C}$ until required for use. After the $3 \mathrm{~h}$ incubation in DM, pili were found on both the SR and the SS organisms (three batches) (for method, see Penn et al., 1976) and, on growing on agar overnight, both formed 'double highlight' colonies (Penn et al., 1977). 
It was important (see Results) that the protein profiles of SS and SR organisms were compared for equal numbers of organisms. Viable counts were done on the two types of organisms at the end of the $3 \mathrm{~h}$ induction period during the test for resistance to killing by FHS (see above). In 15 tests on replicate samples of different batches of SR and SS organisms, the viable counts on the SR organisms at the end of the induction period and before centrifuging to prepare the bulked sample (see above) were 101, 92, 103, 95, 98, 96, 108, 105, 100, 94, 101, $88,98,99$ and $98 \%$ of those of the control SS organisms. The fact that these counts on the two types of gonococci were so similar is not surprising because in the preparation of the SR and SS (control) organisms all flasks were inoculated with the same numbers of the same cultures, contained the same medium with the addition of the same RBC ultrafiltrate either untreated or acid-inactivated and were incubated for only a short time ( $3 \mathrm{~h})$. Furthermore, a typical check on total counts showed the ratio of total to viable counts to be 1.4 and 1.5 for the SR and SS gonococci respectively. The higher figures for the total counts are explained by the presence of pairs, tetramers and hexamers; these were not excessive and individual members of the conglomerates were counted.

Protein profiles of lysates of $S R$ and $S S$ gonococci by SDS-PAGE. Equal numbers $\left(4 \times 10^{7}\right)$ of SR and SS gonococci [strain BS4 (agar)] were suspended in $60 \mu \mathrm{l}$ buffer [0.062 $\mathrm{M}$-Tris $/ \mathrm{HCl}$ buffer, $\mathrm{pH} 6.8$, containing $2 \%(\mathrm{w} / \mathrm{v})$ SDS, $10 \%(\mathrm{v} / \mathrm{v})$ glycerol, $5 \%(\mathrm{v} / \mathrm{v}) 2$-mercaptoethanol and $0.001 \%$ bromophenol blue], and heated to $100{ }^{\circ} \mathrm{C}$ for 5 min. The heated suspensions, or appropriate dilutions (see Figs 1 and 2), were loaded directly on to gels for SDSPAGE. The method of Laemmli (1970) was used with a linear gradient of $8-20 \%$ acrylamide as described by Hames (1981) in a slab system (Raven Scientific). Electrophoresis was carried out at $30 \mathrm{~mA}$ in a buffer $(0 \cdot 025 \mathrm{M}-$ Tris, $0 \cdot 192 \mathrm{M}$-glycine, $\mathrm{pH} 8 \cdot 3$ ) containing $0 \cdot 1 \%(\mathrm{w} / \mathrm{v})$ SDS until the bromophenol blue tracking dye was about 10 $\mathrm{mm}$ from the end of the gel. Gels were stained with silver by the method of Okley et al. (1980).

Marker proteins (Bio-Rad) were lysozyme, $14.4 \mathrm{kDa}$; soyabean trypsin inhibitor, 21.5; carbonic anhydrase, 31.0; ovalbumin, 45.0; BSA, 66.2; and phosphorylase $b, 92 \cdot 5$; also myosin (Sigma), $205 \mathrm{kDa}$. For Fig. 1, lane 1 (SS lysate) and lane 2 (SR lysate) were run together. Lanes 3 (LPS), 4 (mixture of marker proteins) and 5 (myosin) were run separately from one another and from lanes 1 and 2 , but in all cases they were run concurrently with a sample of the more plentiful SS lysate. The gels were lined up according to their origins and dye fronts.

Purified LPS of SS organisms. This was prepared by the method of Tan et al. (1986) and detected on SDS-PAGE by the method of Tsai \& Frasch (1982).

Immunization of rabbits with SR and SS gonococci. New Zealand White rabbits (three for SR organisms and three for SS organisms) received intradermally at several sites about $3 \times 10^{8}$ gonococci in PBS mixed with 2 vols complete Freund's adjuvant. Then, at approximately fortnightly intervals, second, third and fourth injections were performed intraperitoneally, intramuscularly and subcutaneously respectively with about $2 \times 10^{8}$ gonococci in PBS mixed with an equal volume of incomplete Freund's adjuvant. Rabbits were bled 2 weeks after the last injection. Sera were separated, heated $\left(56^{\circ} \mathrm{C}, 45 \mathrm{~min}\right)$ and kept at $-20^{\circ} \mathrm{C}$. Separate mixtures of the three anti-SR sera and the three anti-SS sera were used for immunoblotting to provide maximum coverage of antibodies.

Absorption of anti-SR rabbit serum and FHS by SS organisms. SS organisms were grown as described by Tan et al. (1986), centrifuged $\left(3000 \mathrm{~g}, 4^{\circ} \mathrm{C}, 15 \mathrm{~min}\right)$, washed once and suspended in PBS containing BSA $(0 \cdot 1 \%$, w/v) to give a suspension $\left(2-3 \mathrm{ml} ; 10^{10}\right.$ organisms $\left.\mathrm{ml}^{-1}\right)$. The suspension was dispensed into $100 \mu \mathrm{l}\left(10^{9}\right.$ gonococci) portions and stored at $-70^{\circ} \mathrm{C}$. The mixed anti-SR serum or the FHS $(50 \mu \mathrm{l}+450 \mu \mathrm{l}$ PBS $)$ was absorbed with SS organisms $\left(100 \mu \mathrm{l} ; 10^{9}\right.$ gonococci) on a rotator for $4 \mathrm{~h}$ at $4{ }^{\circ} \mathrm{C}$. The organisms were removed by centrifugation $(12500 \mathrm{~g}, 5 \mathrm{~min}$, room temperature) on a microfuge (MSE) and the absorption repeated twice with fresh SS organisms. The absorbed serum was either used immediately or stored at $-70^{\circ} \mathrm{C}$.

Immunoblotting of protein profiles with rabbit antisera against $S S$ and $S R$ gonococci. After SDS-PAGE of proteins from equal numbers (about $2 \times 10^{7}$ ) of SS or SR gonococci (see above), immunoblotting was carried out by the method of Towbin et al. (1979) as modified by Bailey et al. (1985). The proteins were transferred to nitrocellulose membranes $(0.45 \mu \mathrm{m}$ thick, Sartorius). To eliminate interference by LPS as much as possible and in contrast to the LPS studies of Tan et al. (1986), Tween 20 was included in all buffers since it causes elution of gonococcal LPS from the membranes (Caldwell \& Hitchcock, 1984). The membranes were then gently agitated in $3 \%(w / v)$ BSA in PBS for $1 \mathrm{~h}$ at room temperature before incubation for $2 \mathrm{~h}$ with either unabsorbed or absorbed rabbit antisera at $1: 100$ dilution in PBS containing BSA $(0 \cdot 1 \%, \mathrm{w} / \mathrm{v})$. After washing (five times, PBS $100 \mathrm{ml}$ ), the membranes were reacted for $1 \mathrm{~h}$ with goat anti-rabit IgG conjugated with horseradish peroxidase (Sigma) diluted $1: 2000$ in PBS (50 $\mathrm{ml}$ ) containing BSA $(0.1 \%, \mathrm{w} / \mathrm{v})$ and again washed (five times, PBS $100 \mathrm{ml})$. Bound conjugate was localized and visualized by a mixture of $1.5 \mathrm{ml} \mathrm{2} \%$ (w/v) 4-chloro-1-naphthol (Sigma) in methanol, $25 \mu \mathrm{l} 30 \% \mathrm{H}_{2} \mathrm{O}_{2}$ and $100 \mathrm{ml}$ $50 \mathrm{~mm}-\mathrm{Tris} / \mathrm{HCl}$ buffer, $\mathrm{pH} 7 \cdot 2$.

Immunoblotting of protein profiles with FHS. After SDS-PAGE of the proteins from equal numbers (about $2 \times$ $\left.10^{7}\right) \mathrm{SS}$ or SR gonococci, transfer to nitrocellulose membranes and reaction with either unabsorbed or absorbed FHS ( $1: 50$ dilution) was carried out as described above for the rabbit antisera. The membranes were then reacted with either goat anti-human IgG or IgM conjugated to horseradish peroxidase (Sigma) as for the goat anti-rabbit $\mathrm{IgG}$ and the remainder of the procedure was the same. 
Table 1. Effect of CAM on induction of N. gonorrhoeae strain BS4 (agar) to serum resistance by an ultrafiltrate of guinea-pig serum

In all but one experiment (1) the figures are the means of duplicate samples. The CAM concentration was $0.57 \mu \mathrm{g} \mathrm{ml}^{-1}$ in experiments $1-4$, and $0.50 \mu \mathrm{g} \mathrm{ml}^{-1}$ in experiments $5-9$. The results are expressed as the number of c.f.u. recovered after incubation with $\mathrm{FHS}$ for $40 \mathrm{~min}$ at $37^{\circ} \mathrm{C}$ as a percentage of the number recovered after a similar incubation with heat-inactivated $\left(56^{\circ} \mathrm{C}, 30 \mathrm{~min}\right)$ human serum; for details of the test see Patel et al. (1984b). Figures in parentheses represent percentage recovery of the inoculum in the incubation period.

\begin{tabular}{ccc} 
& $\begin{array}{c}\text { Percentage serum resistance of organisms after treatment with an } \\
\text { ultrafiltrate of guinea-pig serum for } 3 \mathrm{~h} \text { at }\end{array} 7^{\circ} \mathrm{C}$ with CAM \\
\cline { 2 - 3 } Expt & Absent & Present \\
1 & $>95(>95)$ & $24(75)$ \\
2 & $87(74)$ & $2(61)$ \\
3 & $48(53)$ & $<2(38)$ \\
4 & $>95(76)$ & $32(65)$ \\
5 & $56(>95)$ & $4(49)$ \\
6 & $72(>95)$ & $10(80)$ \\
7 & $>95(>95)$ & $6(>95)$ \\
8 & $>95(>95)$ & $35(90)$ \\
9 & $86(72)$ & $<2(>95)$
\end{tabular}

Table 2. Effect of NEO on induction of $N$. gonorrhoeae strain BS4 (agar) to serum resistance by an ultrafiltrate of guinea-pig serum

The figures are the results from single samples when NEO was absent, but the means of two to four similar replicates when NEO was present. The NEO concentration was $2.6 \mu \mathrm{g} \mathrm{ml}^{-1}$. The results are expressed as for Table 1 .

$\begin{array}{ccc}\text { Expt } & \begin{array}{c}\text { Percentage serum resistance of organisms after treatment with an } \\ \text { ultrafiltrate of guinea-pig serum for } 3 \mathrm{~h} \text { at } 37^{\circ} \mathrm{C} \text { with NEO }\end{array} \\ 1 & \text { Absent } & \text { Present } \\ 2 & >95(>95) & 48(>95) \\ 3 & 34(>95) & <2(>95) \\ 4 & >95(>95) & 65(>95) \\ 5 & >95(>95) & <2(79) \\ 6 & >95(>95) & 20(40) \\ 7 & 90(>95) & 4(80) \\ 8 & 53(>95) & <2(>95) \\ 9 & >95(>95) & 35(50) \\ & >95(>95) & 54(59)\end{array}$

\section{RESULTS}

Effect of CAM and NEO on induction of BS4 (agar) to serum resistance by an ultrafiltrate of guinea-pig serum

The results in Tables 1 and 2 show that treatment with CAM and NEO, at concentrations which in only 3 of 18 experiments ( 3 and 5 in Table 1 , and 5 in Table 2) reduced the inoculum to below $50 \%$, inhibited induction of serum resistance.

\section{Comparison of proteins present in whole-cell lysates of SS and SR organisms}

Protein profiles of whole-cell lysates of equal numbers $\left(4 \times 10^{7}\right)$ of SS (lane 1) and SR (lane 2) organisms separated on gradient SDS-PAGE are shown in Fig. 1. The only differences detected between SR and SS organisms were in two minor lines; the SR organisms gained a high- $M_{\mathrm{r}}$ protein A (approx. $205 \mathrm{kDa}$ ) and lacked a low- $M_{\mathrm{r}}$ protein $\mathrm{B}$ (approx. $16 \mathrm{kDa}$ ) as compared to the proteins of the SS organisms. In order to see these differences of minor lines, the gels had to be overloaded with respect to other proteins (Fig. 1). The differences were, however, reproducible 


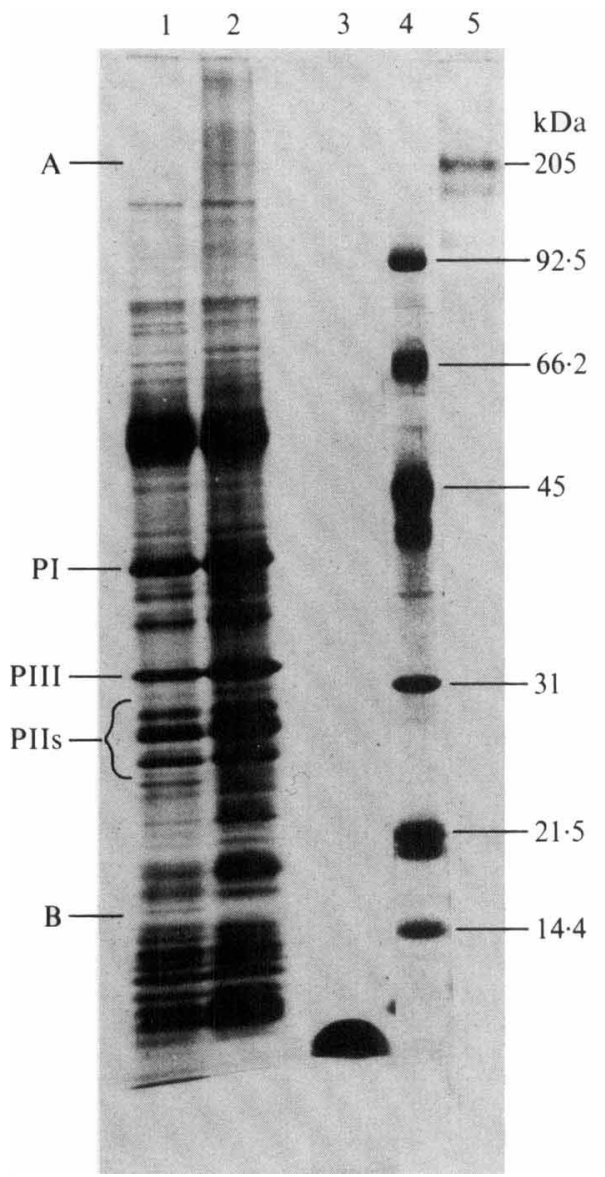

Fig. 1



Fig. 2

Fig. 1. Silver-stained SDS-PAGE (8-20\% acrylamide linear gradient) gels. Lanes 1 and 2, whole-cell lysates of BS4 (agar): SS organisms (lane 1) and SR organisms (lane 2) $\left(4 \times 10^{7}\right.$ for both). Lane 3, purified LPS from SS organisms (about $5 \mu \mathrm{g}$ ); lane 4, a mixture of marker proteins (see Methods); lane 5 , marker myosin. Lanes 1 and 2 were run together; lanes 3, 4, and 5 were run separately from one another and from lanes 1 and 2 (see Methods). The gels were lined up according to their origins and dye fronts. PI, PII and PIII indicate the areas of the principal outer-membrane proteins.

Fig. 2. Silver-stained SDS-PAGE (8-20\% acrylamide linear gradient) gels of whole-cell lysates of BS4 (agar). Lanes 1 and 2, SR (lane 1) and SS (lane 2) organisms (6 $\times 10^{6}$ for both); lanes 3 and 4, SR (lane 3) and SS (lane 4) organisms (1.2 $\times 10^{6}$ for both); lanes 5 and 6, SR (lane 5) and SS (lane 6) organisms (0.6 $\times 10^{6}$ for both). The lysates were prepared from batches of SR and SS organisms which were different from those used for Fig. 1.

in most experiments; thus, in comparisons of 14 different pairs of SR and SS organisms, protein A was seen 10 times in SR organisms and never in SS organisms; and protein B was seen 9 times in SS organisms and never in SR organisms. Also, protein A was not seen in grossly overloaded profiles from $4 \times 10^{8} \mathrm{SS}$ gonococci (prepared in the absence of acid-inactivated ultrafiltrate). Proteins A and B migrated at positions different from purified LPS of SS organisms (lane 3).

Fig. 1 also indicated that many proteins were present in larger amounts in the SR than SS organisms although this was not so for all (e.g. those in the 65-80 kDa region). To confirm this indication, the comparisons of gel profiles of equal numbers of SR and SS organisms were done with progressively decreasing amounts to a point where most lines from the SS organisms were very faint (Fig. 2). As expected, some lines disappeared as the numbers of gonococci were reduced, but the titration clearly showed that $\mathrm{SR}$ organisms contained greater amounts than the 


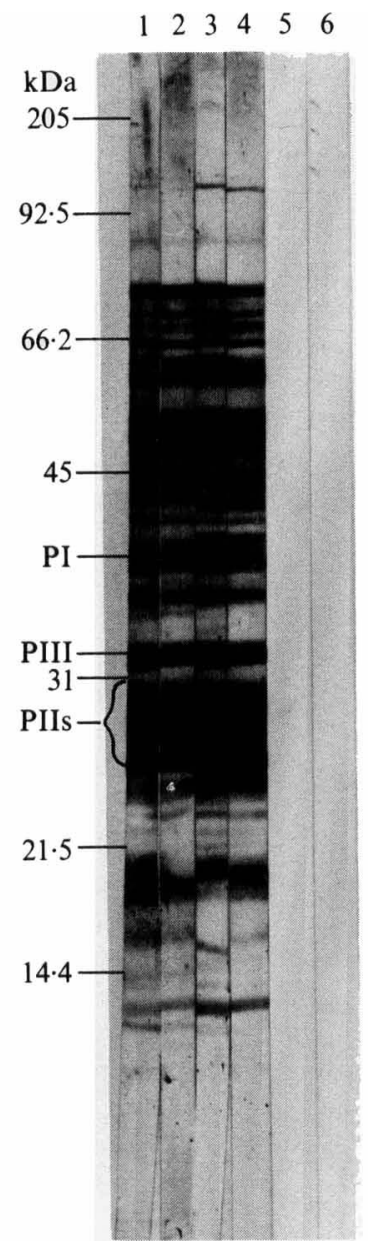

Fig. 3

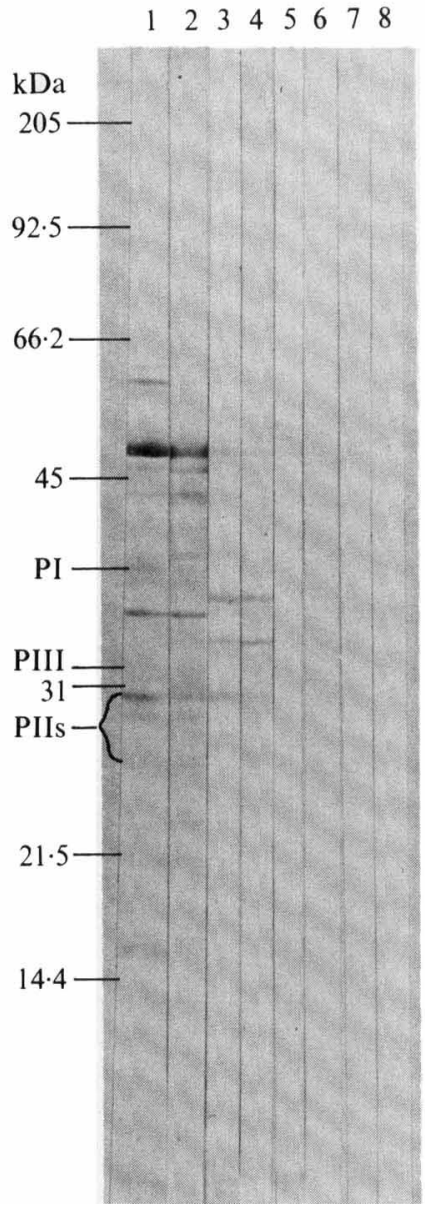

Fig. 4

Fig. 3. Immunoblots of SDS-PAGE gels of whole-cell lysates of SR and SS organisms (about $2 \times 10^{7}$ for both) with anti-SR and anti-SS rabbit sera and with anti-SR serum after absorption with SS organisms. Sera were used at 1:100 dilution. Lanes 1 and 2, anti-SR serum: lane 1, SR organisms; lane 2, SS organisms. Lanes 3 and 4, anti-SS serum: lane 3, SR organisms; lane 4, SS organisms. Lanes 5 and 6, absorbed anti-SR serum: lane 5, SR organisms; lane 6, SS organisms.

Fig. 4. Immunoblots of SDS-PAGE gels of whole-cell lysates of SR and SS organisms (about $2 \times 10^{7}$ for both). Lanes 1-4, with FHS, using methods which detect IgG (lane 1, SR organisms; lane 2, SS organisms), and those which detect IgM (lane 3, SR organisms; lane 4, SS organisms). Lanes 5-8, with FHS absorbed with SS organisms, using methods which detect IgG (lane 5, SR organisms; lane 6, SS organisms), and those which detect IgM (lane 7, SR organisms; lane 8, SS organisms).

SS organisms of many proteins, including the three principal outer-membrane proteins. The results shown in Fig. 2 were repeated five times with five different batches of SR and SS organisms.

\section{Immunoblotting of SDS-PAGE protein profiles of lysates of SR and SS gonococci with anti-SR} and anti-SS rabbit sera

Immunoblotting of protein profiles of lysates of SR and SS organisms with unabsorbed antiSR and anti-SS serum and staining for IgG (Fig. 3, lanes 1, 2, 3 and 4) showed about 35-40 lines; 
good transfer and blotting of proteins from the original gels over the range 12-100 kDa were obtained. Although occasional differences in intensity of bands can be seen (e.g. in the 80-85, 40-45 and 34-36 kDa region) no marked differences between the profiles for SR and SS organisms were detected, no matter whether the immunoblotting was done with either anti-SR (lanes 1 and 2) or anti-SS (lanes 3 and 4) sera. The two types of sera detected different antigens in some regions (e.g. at about $33,37,45$ and $95 \mathrm{kDa}$ ) of the profiles of both types of organisms. The high- $\boldsymbol{M}_{\mathrm{r}}$ protein A (approx. $205 \mathrm{kDa}$ ) was not detected by either anti-SR or anti-SS rabbit sera; and the immunoblots in the $16 \mathrm{kDa}$ region were not clear enough to differentiate the presence or absence of the low- $M_{\mathrm{r}}$ protein B. Reactions with LPS components which would have occurred in the low- $M_{\mathrm{r}}$ regions of the gels (see Fig. 1) were not seen (Fig. 3; all lanes) because the method of immunoblotting employed was not designed to detect LPS (see Methods). Strikingly, when the anti-SR serum was absorbed with SS organisms and used for immunoblotting, no reactions at all were detected for lysates of both SR and SS organisms (Fig. 3, lanes 5 and 6). The results in Fig. 3 were repeated five times with five different batches of SR and SS organisms.

\section{Immunoblotting of SDS-PAGE protein profiles of lysates of SR and SS gonococci with FHS}

In immunoblotting of protein profiles of lysates with FHS and staining for IgG reactions, some (about 15 ) of the 35-40 lines revealed by the hyper-immune rabbit antisera were detected (Fig. 4, lanes 1 and 2). An antigenic protein of about $50 \mathrm{kDa}$ was prominent in both lysates and, although the majority of the other lines were also common, there were some differences in intensity of reaction (Fig. 4, lanes 1 and 2). Staining for IgM reactions showed only six faint lines (Fig. 4, lanes 3 and 4) with no differences between SR and SS organisms. In both the IgG and IgM reactions, proteins in the principal outer-membrane region were not markedly reactive, and only two of the proteins detected by IgM were clearly detected by IgG. Absorption of the FHS by SS organisms removed the IgG and IgM antibodies that reacted with the antigens of both SR and SS organisms (Fig. 4, lanes 5-8), indicating no significant differences between these antigens for the types of organisms. As for Fig. 3, no reactions with LPS components were seen in the low $-M_{\mathrm{r}}$ region. The results in Fig. 4 were repeated five times with five different batches of SR and SS organisms.

\section{DISCUSSION}

CAM and NEO prevent protein synthesis and, at bacteriostatic concentrations, they inhibited induction of resistance (Tables 1 and 2). Complete inhibition was not achieved in some experiments, but the antibiotic concentrations could not be raised without being bactericidal, which was evident to some extent in 3 of 18 experiments (Tables 1 and 2). The antibiotics were added for the whole incubation period because $3 \mathrm{~h}$ is the minimum time needed for induction of resistance $(80-95 \%)$ in control samples; indeed, occasionally only partial resistance may be achieved (see experiments 3 and 5 in Table 1 and 2 and 7 in Table 2). The antibiotic experiments indicate that induction of resistance is protein-mediated, which is not surprising. They do not, however, prove that the determinant is a protein.

Possible changes in proteins accompanying induction of serum resistance were investigated by first examining protein profiles and then immunoblotting them with hyper-immune rabbit antisera. Both methods indicated the important fact that the protein changes accompanying induction to resistance are relatively minor.

The SDS-PAGE protein profiles of lysates of the same numbers of SS and SR organisms (Fig. 1) showed a protein A of approximately $205 \mathrm{kDa}$ present in SR organisms but not detectable in SS organisms and a protein B of approximately $16 \mathrm{kDa}$ present in SS organisms but not detected in SR organisms. Both lines were faint compared with other more prominent proteins but were reproducible in the majority of experiments. The appearance of protein $A$ or the disappearance of protein B did not appear to be related to the LPS changes accompanying the acquisition of resistance (Tan et al., 1986). Neither protein migrated near to LPS itself (Fig. 1, lane 3) nor to proteins of molecular mass $23-36 \mathrm{kDa}$, which observations on other strains of gonococci have 
shown can form complexes with LPS (Hitchcock, 1984). The possibility that the $16 \mathrm{kDa}$ protein might be due to piliation of the SS organisms in contrast to the SR organisms does not seem likely because pili were found on both SS and SR organisms.

The gels, which were overloaded to demonstrate proteins A and B, also indicated that many proteins were present in SR organisms in larger amounts than in SS organisms (Fig. 1). This was confirmed by comparing the profiles from equal but decreasing numbers of the two types of gonococci (Fig. 2); the three principal outer-membrane proteins were amongst those proteins present in larger amounts in the SR organisms. An increase in outer-membrane proteins might be explained by the need for other membrane constituents to make up for the loss of LPS components that accompanies induction of serum resistance (Tan et al., 1986).

Immunoblotting with the anti-SS and anti-SR sera (Fig. 3) demonstrated 35-40 antigenic proteins but did not reveal proteins additional to $A$ and $B$ that were either present or absent in SS or SR organisms. The 35-40 proteins in the SR and SS organisms appeared similar in nature. First, although anti-SR and anti-SS sera detected different antigens in some regions of the profiles (e.g. at about 33, 37, 45 and $95 \mathrm{kDa}$ ), no marked differences between SR and SS organisms were found whichever antiserum was used although differential staining of some bands was seen (Fig. 3, lanes 1-4). Second, when anti-SR serum was absorbed with SS organisms, a procedure which might have left antibodies exclusive to antigens present in SR, but not SS organisms, there were no reactions (Fig. 3, lane 5) with any of the 35-40 antigens that had immunoblotted in the profile of SR organisms with unabsorbed antiserum (Fig. 3, lane 1). As expected, no reactions were obtained when the absorbed anti-SR serum was reacted with the SS profile (Fig. 3, lane 6).

Immunoblotting with FHS and staining for IgG reactions also indicated no major differences between SR and SS organisms. Not surprisingly, the IgG of FHS (Fig. 4, lanes 1 and 2) detected only some (about 15) of the antigens (35-40) demonstrated by the hyper-immune rabbit antisera. No substantial differences emerged between SR and SS organisms. Again, this fact was driven home by the lack of detection of antigens by IgG when profiles of both types of organisms were immunoblotted by FHS absorbed with SS organisms (Fig. 4, lanes 5 and 6).

The reactions of the IgM in FHS with the protein profiles (Fig. 4, lanes 3 and 4) were generally weaker than those for IgG (Fig. 4, lanes 1 and 2) and only six lines were seen. Again, there were no marked differences between SR and SS organisms and no reactions with FHS absorbed with SS organisms (Fig. 4, lanes 7 and 8). Remembering that IgM is responsible for most of the bactericidal activity of FHS which is neutralizable by the LPS of SS organisms, the weak reactions with a few proteins of SR and SS organisms, and the lack of any differences between them, are in stark contrast to the strong and different reactions given by the LPS components of SS and SR organisms with IgM (Tan et al., 1986).

In essence, the changes in proteins accompanying the acquisition of serum resistance are not so profound as those in the structure of LPS which in SS organisms appears to be the target for bactericidal IgM of FHS; and, in contrast to LPS, protein reactions with IgM are weak and show no differences between SR and SS organisms. Hence, the protein changes are less likely than those in the LPS to be directly involved in serum resistance. A reasonable working hypothesis is that acquired resistance to FHS probably arises from loss of the target site(s) for bactericidal IgM on the LPS (see Tan et al., 1986). The increases in amounts of some proteins in SR organisms might result from the need to restore outer-membrane conformation after such profound changes in LPS. Although proteins almost certainly mediate the LPS changes, the roles of proteins $A$ and $B$ in acquisition of resistance, if any, are unknown.

We wish to thank Dr A. Cockayne for advice on immunoblotting and staining procedures.

\section{REFERENCES}

Bailey, M. J., Penn, C. W. \& Cockayne, A. (1985). Evidence for the presence of lipopolysaccharide in Treponema phagedenis (biotype Reiterii) but not in Treponema pallidum (Nichols). FEMS Microbiology Letters 27, 117-121.
Brooks, G. F., Gotschlich, E. C., Holmes, K.K., SAWYER, W. D. \& Young, F. E. (1978). Immunobiology of Neisseria gonorrhoeae. Washington, DC: American Society for Microbiology.

Caldwell, H. D. \& HitchCock, P. J. (1984). 
Monoclonal antibody against a genus-specific antigen of Chlamydia species: location of the epitope on chlamydial lipopolysaccharide. Infection and Immunity 44, 306-314.

Hames, B. D. (1981). An introduction to polyacrylamide gel electrophoresis. In Gel Electrophoresis of Proteins - a Practical Approach, pp. 74-75. Edited by B. D. Hames \& D. Rickwood. Washington, DC: IRL Press.

HITCHCOCK, P. J. (1984), Analyses of gonococcal lipopolysaccharide in whole-cell lysates by sodium dodecylsulphate-polyacrylamide gel electrophoresis: stable association of lipopolysaccharide with the major outer membrane protein (protein I) of Neisseria gonorrhoeae. Infection and Immunity 46, 202212.

LAEMMLI, U. K. (1970). Cleavage of structural proteins during the assembly of the head of bacteriophage T4. Nature, London 227, 680-685.

Martin, P. M. V., Patel, P. V., Parsons, N. J. \& SMITH, H. (1981). Induction of phenotypically determined resistance of Neisseria gonorrhoeae to human serum by factors in human serum. Journal of General Microbiology 127, 213-217.

Martin, P. M. V., Patel, P. V., Parsons, N. J. \& SMITH, H. (1982). Induction in gonococci of phenotypic resistance to killing by human serum by human genital secretions. British Journal of Venereal Diseases 58, 363-365.

Martin, P. M. V., Patel, P. V., Clay, J. C., Parsons, N. J. \& SMITH, H. (1984). Induction by human serum of resistance to serum in Neisseria gonorrhoeae: a clinical survey of patients with gonorrhoea. British Journal of Venereal Diseases 60, 151-153.

OKLEY, B. R., KIRSCH, D. R. \& MORRIS, N. R. (1980). A simplified ultrasensitive silver stain for detecting proteins in polyacrylamide gels. Analytical Biochemistry 105, 361-363.

Parsons, N. J., Patel, P. V., Martin, P. M. V., GoldNER, M. \& SMITH, H. (1985). Gonococci in vitro and in vivo: studies of the host and bacterial determinants of gonococcal resistance to killing by human serum and by phagocytes. In The Pathogenic Neisseria, pp. 487-494. Edited by G. K. Schoolnik, G. F. Brooks, S. Falkow, C. E. Frasch, J. S. Knapp, J. A. McCutchan \& S. A. Morse. Washington, DC: American Society for Microbiology.

Patel, P. V., Martin, P. M. V., Goldner, M., Parsons, N. J. \& SMrth, H. (1984a). Red blood cells, a source of factors which induce Neisseria gonorrhoeae to resistance to complement mediated killing by human serum. Journal of General Microbiology 130, 2767-2770.
Patel, P. V., Veale, D. R., Fox, J. E., Martin, P. M. V., Parsons, N. J. \& SMITH, H. (1984b). Fractionation of guinea pig serum for an inducer of gonococcal resistance to killing by human serum: active fractions containing glucopeptides similar to those from human red blood cells. Journal of General Microbiology 130, 2757-2766.

Penn, C. W., Sen, D., Veale, D. R., Witt, K., Parsons, N. J. \& SMITH, H. (1976). Morphological, biological and antigenic properties of Neisseria gonorrhoeae adapted to growth in guinea pig subcutaneous chambers. Journl of General Microbiology 97, 35-43.

Penn, C. W., Veale, D. R. \& Smith, H. (1977). Selection from gonococci grown in vitro of a colony type with some virulence properties of organisms adapted in vivo. Journal of General Microbiology 100 , 147-158.

Tan, E. L., Patel, P. V., Parsons, N. J., Martin, P. M. V. \& SMITH, H. (1986). Lipopolysaccharide alteration is associated with induced resistance of Neisseria gonorrhoeae to killing by human serum. Journal of General Microbiology 132, 1407-1413.

Towbin, H., Staehelin, T. \& GoRdon, J. (1979). Electrophoretic transfer of proteins from polyacrylamide gels to nitrocellulose sheets: procedure and some applications. Proceedings of the National Academy of Sciences of the United States of America 76, 4350-4354.

Tsai, C. M. \& Frasch, C. F. (1982). A sensitive silver strain for detecting lipopolysaccharide in polyacrylamide gel. Analytical Biochemistry 119, 1115-1119.

Veale, D. R., Smith, H., Witt, K. A. \& Marshall, R. B. (1975). Differential ability of colonial types of Neisseria gonorrhoeae to produce infection and an inflammatory response in subcutaneous perforated plastic chambers in guinea pigs and rabbits. Journal of Medical Microbiology 8, 325-335.

Veale, D. R., PENN, C. W. \& SMITH, H. (1981). Factors affecting the induction of phenotypically determined serum resistance of Neisseria gonorrhoeae grown in media containing serum or its diffusible components. Journal of General Microbiology 122, 235-245.

WARD, M. E., WATT, P. J. \& GlyNN, A. A. (1970). Gonococci in urethral exudates possess a virulence factor lost on subculture. Nature, London 227, 382384.

Winstanley, F. P., Blackwell, C. C., Tan, E. L., Patel, P. V., Parsons, N. J., Martin, P. M. V. \& SMITH, H. (1984). Alteration of pyocin-sensitivity pattern of Neisseria gonorrhoeae is associated with induced resistance to killing by human serum. Journal of General Microbiology 130, 1303-1306. 